\title{
Electrogenic Partial Reactions of the SR-Ca-ATPase Investigated by a Fluorescence Method
}

\author{
C. Butscher, M. Roudna, H.-J. Apell \\ Department of Biology, University of Konstanz, Fach M635, D-78457 Konstanz, Germany
}

Received: 21 September 1998/Revised: 18 December 1998

\begin{abstract}
A fluorescence method was adapted to investigate active ion transport in membrane preparations of the SR-Ca-ATPase. The styryl dye RH421 previously used to investigate the $\mathrm{Na}, \mathrm{K}-\mathrm{ATPase}$ was replaced by an analogue, 2BITC, to obtain optimized fluorescence changes upon substrate-induced partial reactions. Assuming changes of the local electric field to be the source of fluorescence changes that are produced by uptake/ release or by movement of ions inside the protein, 2BITC allowed the determination of electrogenic partial reactions in the pump cycle. It was found that $\mathrm{Ca}^{2+}$ binding on the cytoplasmic and on the lumenal side of the pump is electrogenic while phosphorylation and conformational transition showed only minor electrogenicity. $\mathrm{Ca}^{2+}$ equilibrium titration experiments at $\mathrm{pH} 7.2$ in the two major conformations of the protein indicated cooperative binding of two $\mathrm{Ca}^{2+}$ ions in state $\mathrm{E}_{1}$ with an apparent half-saturation concentration, $K_{M}$ of $600 \mathrm{nM}$. In state $\mathrm{P}-\mathrm{E}_{2}$ two $K_{M}$ values, $5 \mu \mathrm{M}$ and $2.2 \mathrm{mM}$, were determined and are in fair agreement with published data. From $\mathrm{Ca}^{2+}$ titrations in buffers with various $\mathrm{pH}$ and from $\mathrm{pH}$ titrations in $\mathrm{P}_{-} \mathrm{E}_{2}$, it could be demonstrated that $\mathrm{H}^{+}$binding is electrogenic and that $\mathrm{Ca}^{2+}$ and $\mathrm{H}^{+}$compete for the same binding site(s). Tharpsigargin-induced inhibition of the Ca-ATPase led to a state with a specific fluorescence level comparable to that of state $\mathrm{E}_{1}$ with unoccupied ion sites, independent of the buffer composition.
\end{abstract}

Key words: Calcium binding - Ion transport - Binding site - Electrogenicity - Styryl dyes - pH dependence

\section{Introduction}

The purpose of the Ca-ATPase in sarcoplasmic reticulum is to pump $\mathrm{Ca}^{2+}$ from the cytoplasm into the lumen of the reticulum to promote in this way muscle relaxation. To fulfill this function on the one hand a high transport capacity is required to allow muscle relaxation in approximately $50 \mathrm{msec}$ and, on the other hand, a concentration gradient of $0.1 \mu \mathrm{M}$ in the cytoplasm and a few millimolar in the lumen has to be maintained in the resting state of muscle cells. Studies on structural and mechanistic properties of the SR-Ca-ATPase are numerous, in accordance with its importance for living organisms, and this protein is one of the best-known ion pumps (Inesi, 1985, Anderson, 1989, Läuger, 1991, Inesi \& Sagara, 1992, Martonosi, 1995, Vilsen, 1995, Zhang et al., 1998). On the basis of the known stoichiometry of 2 $\mathrm{Ca}^{2+}$ transported per ATP utilized (de Meis, 1985; Yu \& Inesi, 1995) and of the electrogenicity of the pump (Yu et al., 1993; Yu, Hao \& Inesi, 1994) the observed $\mathrm{Ca}^{2+}$ concentration gradients across the SR membrane are energetically possible only in the absence of a transmembrane voltage (Walz \& Caplan, 1988). The absence of an electric membrane potential across the SR membrane is caused by a high ionic permeability for monovalent ions (Hasselbach \& Oetliker, 1983).

A consequence of these physiological properties of the SR membranes is that the SR-Ca-ATPase is not directly accessible to electrophysiological investigations. The high leak conductance prohibits the measurements of transmembrane electric events. Therefore, the electrogenicity and the stoichiometry of the $\mathrm{Ca}^{2+}$ pump was controversial for a long time (Läuger, 1991). Recently, clear cut evidence was presented by Yú and collaborators who circumvented the problem of the highly permeable native SR vesicles and demonstrated by experiments with SR Ca-ATPase reconstituted in proteoliposomes 


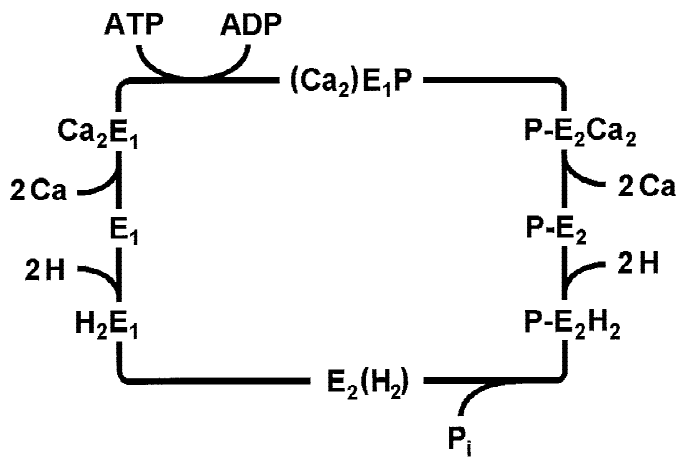

Fig. 1. Simplified pump cycle of the SR-Ca-ATPase on the basis of a $\mathrm{H}^{+} / \mathrm{Ca}^{2+}$ exchange model (Yu et al., 1994). $\mathrm{E}_{1}$ and $\mathrm{E}_{2}$ represent the two basic conformations of the protein in which may be defined by the accessibility of the binding sites for $\mathrm{Ca}^{2+}$ ions on the cytoplasmic or lumenal side of the $\mathrm{SR}$ membrane, respectively. In states $\left(\mathrm{Ca}_{2}\right) \mathrm{E}_{1}-\mathrm{P}$ and $\mathrm{E}_{2}\left(\mathrm{H}_{2}\right)$ the ions are occluded, i.e., they cannot exchange with either aqueous phase. The scheme is based on a transport stoichiometry of 2 $\mathrm{Ca}^{2+} / 2 \mathrm{H}^{+} / 1 \mathrm{ATP}$.

that the stoichiometry is $2 \mathrm{Ca}^{2+} / 2 \mathrm{H}^{+} / 1 \mathrm{ATP}$ and that the pump is electrogenic (Yu et al. 1993, 1994).

The application of fluorescent dyes, such as Oxonol VI, to measure electrogenic ion transport in reconstituted vesicles, however, provides only very restricted insight into the kinetics and electrogenic contributions of partial reactions to the function of ion pumps (Apell \& Bersch, 1987). Therefore a different strategy has been developed to obtain access to such information. In the case of the $\mathrm{Na}, \mathrm{K}-\mathrm{ATPase}$, styryl dyes, especially RH421, are applied successfully to investigate various partial reactions of the pump cycle (Klodos \& Forbush, 1988, Stürmer et al., 1991, Heyse et al., 1994, Apell et al., 1996). The detection mechanism of styryl dyes is based mainly on their electrochromic behavior under specific experimental conditions, i.e., low dye concentrations in the order of $200 \mathrm{nM}$, and excitation at the far red edge of the absorption spectrum (Bühler et al., 1991). This means that an observed fluorescence decrease or increase occurs when a positive charge is imported into or is removed from the protein, respectively. Since the styryl dyes report essentially the change of local electric fields within the protein/membrane dielectric, and to a much lesser extent transmembrane electric potentials, this method can be applied to open membrane fragments (as in the case of the $\mathrm{Na}, \mathrm{K}$-ATPase) or to leaky vesicular membranes (as in the case of SR membranes).

Therefore it is opportune to apply this method to the investigation of the SR-Ca-ATPase. As the basis of our investigations we refer to a pump cycle which we derived from Yu et al. (1994) as shown in Fig. 1. This reaction sequence accounts essentially for all observations with respect to the ion transport mechanism and shows the substrate-dependent partial reactions which are easily accessible to experimental investigation. In the light of the high structural similarities between $\mathrm{Na}, \mathrm{K}$ ATPase and SR-Ca-ATPase (Vilsen, Ramlov \& Anderson, 1997; Vilsen 1998) it may be assumed that, correspondingly, ion-binding and release steps may be the main contributors to the electrogenicity of the SR CaATPase.

The aims of this presentation are as follows: (i) the establishment of an experimental technique using an appropriate styryl dye to investigate electrogenic partial reactions of the SR Ca-ATPase, electrogenic partial reactions being defined as transitions between states of the pump cycle in which electric charge is moved within the protein dielectric perpendicular to the plane of the membrane, (ii) the identification of the electrogenic reaction steps in the pump cycle, and (iii) the presentation of additional evidence for binding of $\mathrm{H}^{+}$ions to the $\mathrm{Ca}^{2+}$ binding sites and for $\mathrm{H}^{+}$counter transport.

\section{Materials and Methods}

Phosphoenolpyruvate, pyruvate kinase, lactate dehydrogenase, NADH, ATP (disodium salt, special quality) were from Boehringer (Mannheim). Tharpsigargin and tricine were purchased from Sigma (München). RH 421 (N-(4-Sulfobutyl)-4-(4-(4-(dipentylamino)phenyl)butadienyl) pyridinium, inner salt), Fura-2 and BAPTA (1,2bis(2aminophenoxy)-ethane- $\mathrm{N}, \mathrm{N}, \mathrm{N}^{\prime}, \mathrm{N}^{\prime}$ tetrasodium salt) were obtained from MoBiTec (Göttingen), EGTA (Ethylenglycol O,O' -bis(2aminoethyl)-N, $\mathrm{N}^{\prime} \mathrm{N}^{\prime}, \mathrm{N}^{\prime}$ tetraacetic acid) and Bis-Tris (Bis(2hydroxyethyl)amino-tris (hydroxymethyl) methane) from Fluka (Buchs, Switzerland). $\mathrm{NaCl}$ (suprapure quality) and all other reagents (at least analytical grade) were from Merck (Darmstadt). 2BITC (1[4-isothiocyanato-n-butyl]-4-[(p-N,N-diethylamino)styryl]pyridinium bromide) was synthesized in the Institute of Organic Chemistry and Macromolecular Chemistry at the University of Düsseldorf, Germany, by M. Birmes and S. Beutner according to Birmes (1995).

SR-Ca-ATPase was prepared by a slight modification of the method of Heilmann et al. (1977) from the psoas muscle of rabbits. The whole procedure was performed at temperatures below $4^{\circ} \mathrm{C}$. The determination of the protein content of the membrane preparation was performed according to Markwell et al. (1978). The most active fractions of the final density gradient separation had a protein content of $2-3 \mathrm{mg} / \mathrm{ml}$. The enzymatic activity was determined by the pyruvate kinase/lactate dehydrogenase linked-assay (Schwartz et al., 1971) in a buffer containing $2 \mu \mathrm{M}$ of free $\mathrm{Ca}^{2+}$. Background enzymatic activity of the isolated preparation was obtained by either quantitative removal of the free $\mathrm{Ca}^{2+}$ by $5 \mathrm{~mm}$ EGTA or addition of $1 \mu \mathrm{M}$ tharpsigargin. The Ca-ATPase specific activity was about 2.5 units $/ \mathrm{mg}$ at $25^{\circ} \mathrm{C}$ (which corresponds to $2.5 \mu \mathrm{mol}$ ATP hydrolyzed per mg protein per min) and could be increased to 3 units/mg in the presence of A23187 and FCCP to short-circuit the membranes completely.

To determine the free $\mathrm{Ca}^{2+}$ concentrations in buffers used for experiments two methods were applied. In the concentration range above $1 \mu \mathrm{M}$ an electrode with the Ca-selective Membrane ETH129 was used. The slope of the linear calibration curve was $25 \mathrm{mV} / \mathrm{pCa}$ in calibration buffers containing $10 \mathrm{~mm}$ EGTA, $1 \mathrm{~mm} \mathrm{MgCl}_{2}, 25 \mathrm{~mm}$

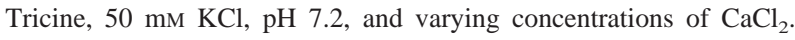
This slope is close to previously published data (Schefer et al., 1986). In the range between $17 \mathrm{nM}$ and $3 \mu \mathrm{M}$ the free $\mathrm{Ca}^{2+}$ concentration was determined fluorimetrically using the ratiometric indicator dye Fura-2 (Grynkiewicz, Poenie \& Tsien, 1985). The calibration was performed with commercially available buffers (MoBiTec, Göttingen). 


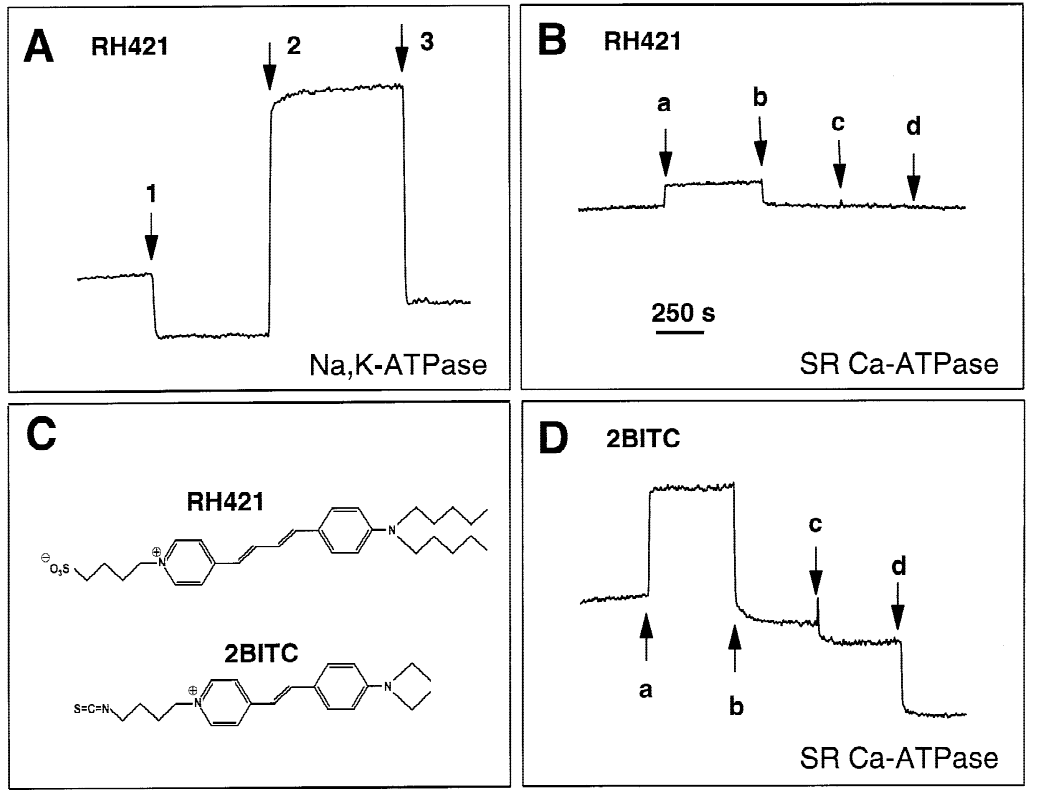

Fig. 2. Investigation of electrogenic partial reactions of the $\mathrm{Na}, \mathrm{K}-\mathrm{ATPase}$ and the SR-Ca-ATPase by electrochromic styryl dyes. $(A)$ The dye RH421 has been successfully applied to study electrogenic reaction steps of the $\mathrm{Na}, \mathrm{K}-\mathrm{ATPa}$ e which can be obtained by substrate additions. (1) + $50 \mathrm{mM} \mathrm{Na}^{+}: \mathrm{E}_{1} \rightarrow \mathrm{Na}_{3} \mathrm{E}_{1},(2)+1$ mM ATP: $\mathrm{Na}_{3} \mathrm{E}_{1} \rightarrow \mathrm{P}-\mathrm{E}_{2}$, (3) $+40 \mathrm{mM} \mathrm{K}{ }^{+}: \mathrm{P} \mathrm{E}_{2}$ $\rightarrow \mathrm{E}_{2}\left(\mathrm{~K}_{2}\right)$. (B) RH421 is not sensitive to substrate-induced reaction sequences in the case of the Ca-ATPase containing SR membranes. To a buffer which initially contains $25 \mathrm{~mm}$ tricine, 50 mм KCl, 1 mм $\mathrm{MgCl}_{2}$ (pH 7.2), 200 nм RH421, and $9 \mu \mathrm{g} / \mathrm{ml}$ protein, following additions were made to give the final concentrations of (a) 0.1 mM EGTA, (b) $190 \mu \mathrm{M} \mathrm{Ca}^{2+}$, (c) $1 \mathrm{~mm} \mathrm{ATP,} \mathrm{(d)}$ $15 \mathrm{mM} \mathrm{Ca}^{2+}$. The maximum fluorescence changes were less than $15 \%$. (C) Chemical structures of the two styryl dyes applied in studies of the Na,K-ATPase, RH421, and of the Ca-ATPase, 2BITC. (D) In contrast to RH421, 2BITC produced significant fluorescence changes when the experiment shown in panel $B$ was repeated with 200 nM 2BITC instead of RH421. A repetition of the experiment in panel $A$ with 200 nM 2BITC gave only small fluorescence changes (not shown).
Fluorescence measurements were performed in a fluorescence spectrometer LS 50B (Perkin Elmer, Überlingen) in quartz cuvettes of 1 or $2 \mathrm{ml}$ effective volume to obtain iontransport specific data. The cuvette holder was thermostated at $20^{\circ} \mathrm{C}$ (if not otherwise mentioned) and equipped with a magnetic stirrer. The styryl dye RH 421, which was applied successfully with the Na,K-ATPase (Heyse et al., 1994, Apell et al., 1996) was used in control experiments. In these experiments the dye concentration was $200 \mathrm{~nm}$, the excitation wavelength was $590 \mathrm{~nm}$ (slit width $15 \mathrm{~nm}$ ), and the emission wavelength $650 \mathrm{~nm}$ (slit with $20 \mathrm{~nm}$ ).

\section{Results}

\section{Optical Detection of Electrogenic Reaction Steps IN THE SR-Ca-ATPASE}

Since the styryl dye RH421 was applied successfully on the Na,K-ATPase to analyze electrogenic partial reactions, we tried to use the same approach with the SRCa-ATPase. In Fig. $2 A$ and $B$ so-called "standard experiments" are shown which are performed with the $\mathrm{Na}, \mathrm{K}-\mathrm{ATP}$ ase and the SR-Ca-ATPase in the presence of $200 \mathrm{~nm}$ RH421. The standard experiment with the Na,KATPase started in a buffer which initially contained 30 mu histidine, 1mm EDTA, 5 mm $\mathrm{MgCl}_{2}, \mathrm{pH} 7.2,200 \mathrm{nM}$ $\mathrm{RH} 421$, and $8 \mu \mathrm{g} / \mathrm{ml}$ protein. The experiment was performed by consecutive addition of substrates to reach well-defined states in the pump cycle of the ion pump. The states obtained in Fig. $2 A$ were $\mathrm{E}_{1}$ (initial state), $\mathrm{Na}_{3} \mathrm{E}_{1}(+50 \mathrm{~mm} \mathrm{NaCl}), \mathrm{P}_{-} \mathrm{E}_{2}(+1 \mathrm{mM} \mathrm{ATP})$ and $\mathrm{E}_{2}\left(\mathrm{~K}_{2}\right)$
(+ 20 mM KCl) (Stürmer et al., 1991; Stürmer \& Apell, 1992). Significant fluorescence changes were observed and could be used to identify and analyze electrogenic reaction steps (for recent review see Apell, 1997). The fluorescence change induced by addition of ATP was in the order of $100 \%$. A corresponding standard experiment with the SR-Ca-ATPase was performed in a buffer initially containing $25 \mathrm{~mm}$ tricine, $50 \mathrm{mM} \mathrm{KCl}, 1 \mathrm{~mm}$ $\mathrm{MgCl}_{2}$, and approximately $200 \mathrm{nM} \mathrm{Ca}^{2+}$ (according to Fura-2 measurements), $\mathrm{pH} 7.2$, and $200 \mathrm{~nm}$ fluorescent dye. About $150 \mathrm{sec}$ after addition of the dye the protein $(9 \mu \mathrm{g} / \mathrm{ml})$ was added. A stable fluorescence intensity was obtained typically after a few minutes. The initial state of the ion pump under this buffer condition was not well defined, we named it $\mathrm{Ca}_{\mathrm{x}} \mathrm{E}_{1}$ with approximately $\mathrm{x} \leqslant$ 1. In the experiment presented in Fig. $2 B$ and $D$ the states induced by substrate addition were $\mathrm{E}_{1}(+0.1 \mathrm{~mm}$ EGTA, $\mathrm{Ca}_{2} \mathrm{E}_{1}\left(190 \mu \mathrm{M} \mathrm{CaCl} \mathrm{Ca}_{2}\right), \mathrm{P}-\mathrm{E}_{2}$ (+ $1 \mathrm{mM}$ ATP), and P-E $\mathrm{Ca}_{2}\left(+15 \mathrm{mM} \mathrm{CaCl}_{2}\right)$. As can be seen from Fig. $2 B$ only the addition of EGTA and $\mathrm{Ca}^{2+}$ in the state $\mathrm{E}_{1}$ produced a fluorescence increase/decrease in the order of $15 \%$. Enzyme phosphorylation and $\mathrm{Ca}^{2+}$ binding in the state $\mathrm{P}-\mathrm{E}_{2}$ could not be detected by significant fluorescence changes $(\Delta F \leqslant 2 \%)$. On the basis of these findings RH421 was rejected as a useful probe to investigate the electrogenic steps of the Ca-pump. After screening of a large number of analogues of a family of styryl dyes which were synthesized in the Institute of Organic Chemistry and Macromolecular Chemistry at the University of Düsseldorf we selected the styryl dye 2BITC 
(Birmes, 1995) as a suitable probe for the Ca-ATPase in membranes of the sarcoplasmatic reticulum (manuscript in preparation). Its structure is shown in Fig. $2 C$. The corresponding standard experiment in the presence of $200 \mathrm{~nm}$ 2BITC is shown in Fig. 2D. It was performed exactly as described above for experiments with RH421. Under this buffer condition, values of the substrateinduced relative fluorescence changes were between $8 \%$ and $40 \%$, sufficient for detailed analysis.

The concentration of 2BITC was varied between 100 and $1600 \mathrm{nM}$ to check the effect of dye concentration on the substrate-specific fluorescence responses. Changing the ratio of dye to Ca-ATPase by a factor of 16 did not significantly alter the relative fluorescence changes after substrate additions. Up to $1,000 \mathrm{~nm}$, the fluorescence intensity increased linearly with concentration, above $1,000 \mathrm{~nm}$ a tendency to saturation became visible (data not shown). Since no covalent binding of 2BITC to the pump protein could be detected we assume that the dye is distributed in the lipid phase as described for the analogue RH421 (Bühler et al., 1991). A series of control experiments was performed to ensure that the substrate-induced fluorescence changes are protein specific responses. Standard experiments for the Ca-ATPase as defined above were performed with protein-free lipid vesicles to check for fluorescence changes induced by interaction of the substrates EGTA, $\mathrm{Ca}^{2+}$, and ATP with the dye 2BITC dissolved in the lipid phase. In addition, experiments were performed with SR membranes incubated for $20 \mathrm{~min}$ at $56^{\circ} \mathrm{C}$ to destroy the enzymatic activity (the residual enzymatic activity was less than $5 \%$ of that before incubation). In both types of control experiments no significant fluorescence changes were observed when $0.1 \mathrm{~mm}$ EGTA, $0.19 \mathrm{mM} \mathrm{Ca}^{2+}$, and $1 \mathrm{~mm}$ ATP were added $\left(\left|\Delta F / F_{0}\right| \leqslant 1 \%\right.$, data not shown). Addition of $15 \mathrm{mM} \mathrm{Ca}^{2+}$ resulted in a fluorescence decrease of $19 \%$ which has to be attributed to a nonspecific effect. This nonspecific effect was investigated separately by titration of the free $\mathrm{Ca}^{2+}$ concentration between $10 \mu \mathrm{M}$ and $100 \mathrm{~mm}$. In lipid vesicles as well as in thermally inactivated SR membranes the fluorescence intensity was not significantly affected in the concentration range between $10 \mu \mathrm{M}$ and $1 \mathrm{mM} \mathrm{Ca}^{2+}$. For higher concentrations the fluorescence declined about $30 \%$ with a half saturating concentration of $13 \mathrm{~mm}$ in vesicles (not shown) and $19 \mathrm{~mm}$ in SR membranes ( $c f$. Fig. 5B). Similar $\mathrm{Ca}^{2+}$-concentration dependent effects were recorded also with tharpsigargin-inhibited SR membranes (not shown).

An obvious result of the experiments with 2BITC (as well as with RH421 to a lesser extent) was that significant fluroescence changes were observed in those partial reactions in which $\mathrm{Ca}^{2+}$ binding or release was involved. In agreement with the mechanism of these styryl dyes, which is predominantly an electrochromic ef- fect in the case of a red-edge excitation, a fluorescence increase is caused by a decrease of an intramembrane electric potential and a fluorescence decrease by a increase of an intramembrane electric potential (Loew et al., 1979; Bühler et al., 1991). This indicates that $\mathrm{Ca}^{2+}$ binding to and release from the Ca-ATPase is an electrogenic event by which the ions move through part of the protein dielectric to shuttle between binding sites and the aqueous phase.

\section{Inhibition of the SR-Ca-ATPase by Tharpsigargin}

Tharpsigargin is known to be a potent and specific inhibitor of the SR-Ca-ATPase (Inesi \& Sagara, 1992) which binds stoichometrically to the enzyme (Sagara \& Inesi, 1991) and stabilizes the transmembrane region of the ATPase (De Meis \& Inesi, 1992). To test the effect of tharpsigargin on the 2BITC-labeled membrane preparations, standard experiments were performed in which tharpsigargin was added to a final concentration of 0.5 $\mu \mathrm{M}$ (from a $1 \mathrm{~mm}$ solution in DMSO) under various substrate conditions. In Fig. $3 A$ an experiment is shown in which tharpsigargin was present before the series of additions of the standard experiment as shown in Fig. $2 D$. In contrast to all other additions (EGTA, $\mathrm{Ca}^{2+}$, ATP) a steady-state level of fluorescence was obtained only very slowly $(<500 \mathrm{sec})$. The time course to reach steady state depended on the tharpsigargin concentration (not shown). Subsequent additions of $0.1 \mathrm{~mm}$ EGTA, $190 \mu \mathrm{M} \mathrm{Ca}^{2+}$ and $1 \mathrm{~mm}$ ATP induced only minor fluorescence changes. Only addition of $15 \mathrm{mM} \mathrm{Ca}^{2+}$ caused a significant drop of the fluorescence level. A synopsis of the experiments in which tharpsigargin was added in different states of the pump cycle is shown in Fig. $3 B$. Addition of the tharpsigargin always led to a fluorescence increase from a level of the standard experiment without tharpsigargin to the level of the inactivated enzyme, independent of the substrate composition in the buffer. A comparison of the fluorescence intensities after the second addition of $\mathrm{Ca}^{2+}(15 \mathrm{~mm})$ reveals on the one hand the nonspecific effect of the high $\mathrm{Ca}^{2+}$ concentration on 2BITC, since the fluorescence decrease in the presence of tharpsigargin cannot be caused by a proteinspecific function, and, on the other hand, that the inhibitor addition in the presence of high $\mathrm{Ca}^{2+}$ initiated a transition of the ion pump into its inhibited state and this protein-specific reaction is accompanied by a significant fluorescence increase. This is an indication of an electrogenic contribution of the transition into the inhibited state of the SR-Ca-ATPase.

The effect of the tharpsigargin concentration on fluorescence intensity is shown in Fig. $3 C$. Increasing concentrations of tharpsigargin were added to 2BITClabeled preparations in standard buffer and the corresponding increase of fluorescence intensity was recorded 

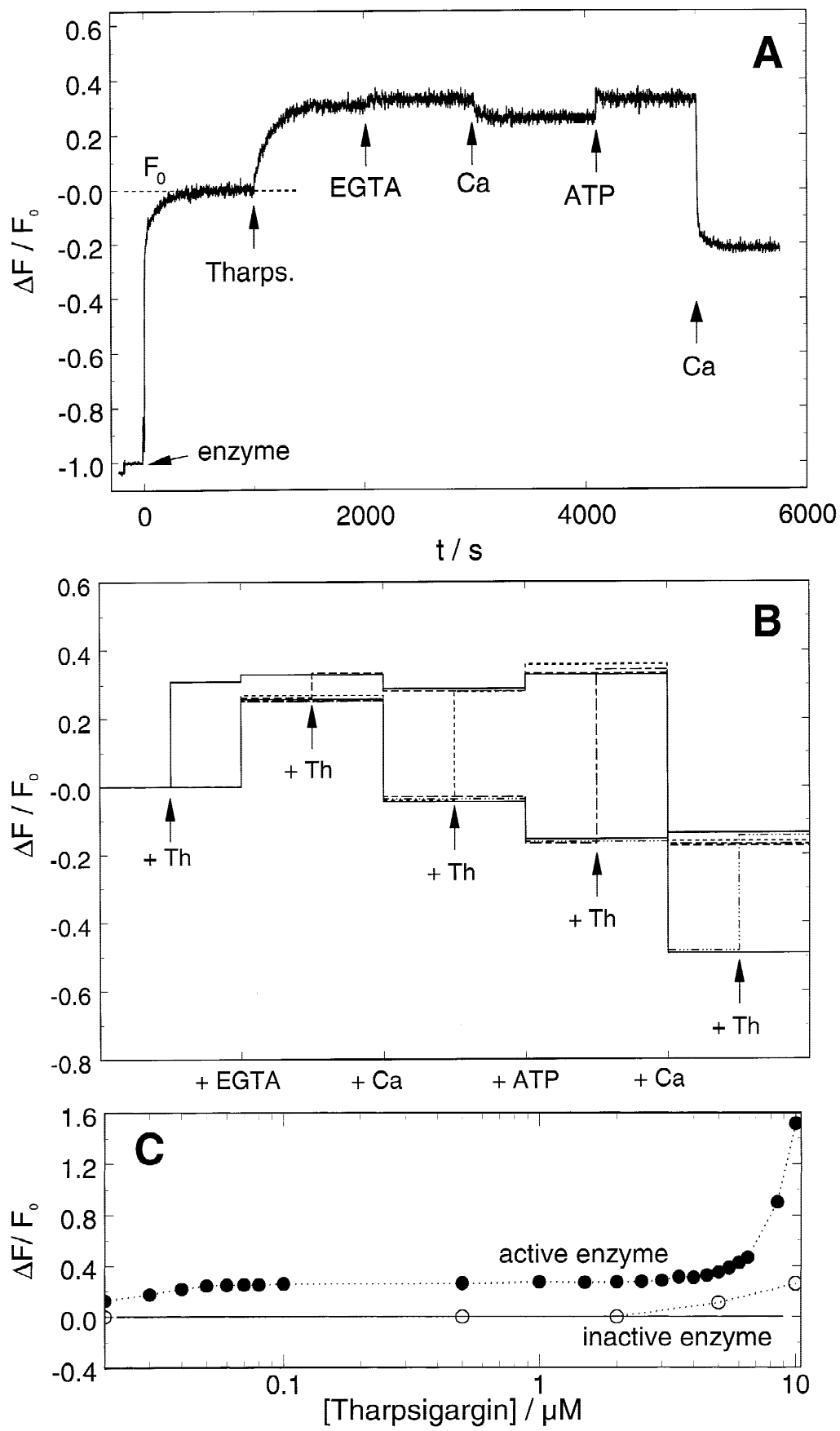

Fig. 3. Effect of tharpsigargin on 2 BITC labeled membrane preparations. The buffer conditions were the same as shown in Fig. 2B. (A) Standard experiment in the presence of $0.5 \mu \mathrm{M}$ tharpsigargin. The fluorescence intensity was normalized to the level prior to addition of the inhibitor, $F_{0}$. The inhibited enzyme produced only small intensity changes when $0.1 \mathrm{mM}$ EGTA, $190 \mu \mathrm{M} \mathrm{Ca}^{2+}$, and 1 mM ATP were added. Addition of $15 \mathrm{mM} \mathrm{Ca}^{2+}$ led to an partly nonspecific drop of $40 \%$. (B) Tharpsigargin was added to the membrane preparation at various stages of the standard experiment $(+\mathrm{Th})$. In each substrate-specific state the same tharpsigargin-induced fluorescence level was observed independent of the state at which the inhibitor was added. $(C)$ Concentration dependence of the tharpsigargin-induced fluorescence increases. Untreated and thermally inactivated preparations are compared. The strong fluorescence increase above 5 $\mu \mathrm{M}$ tharpsigargin is assigned to a nonspecific interaction between inhibitor and dye since it was observed in both membrane preparations in a similar way.

up to a concentration of $10 \mu \mathrm{M}$. In a concentration range of tharpsigargin up to $5 \mu \mathrm{M}$ the fluorescence increase was $\sim 27 \%$ with respect to $F_{0}$. The half-saturating concentration for this effect was $\leqslant 10 \mathrm{nM}$. When, in a control experiment, the inhibitor was added to thermally inactivated ATPases in SR membranes (see above) no 2BITC-fluorescence change was observed. Above $5 \mu \mathrm{M}$ tharpsigargin, the fluorescence increased strongly with concentration and this effect was interpreted as a nonspecific artifact of the inhibitor as a lipid-soluble com- pound on the fluorescence of the dye since it could be observed also with thermally inactivated preparations.

\section{Calcium Titration in State $E_{1}$ of the SR-Ca-ATPase}

An additional control for the detection of $\mathrm{Ca}^{2+}$ binding by the fluorescence decrease was the reproduction of the known binding affinity of the Ca-ATPase. To buffer containing $25 \mathrm{~mm}$ tricine, $50 \mathrm{mM} \mathrm{KCl}, 1 \mathrm{mM} \mathrm{MgCl}_{2}, \mathrm{pH}$ 

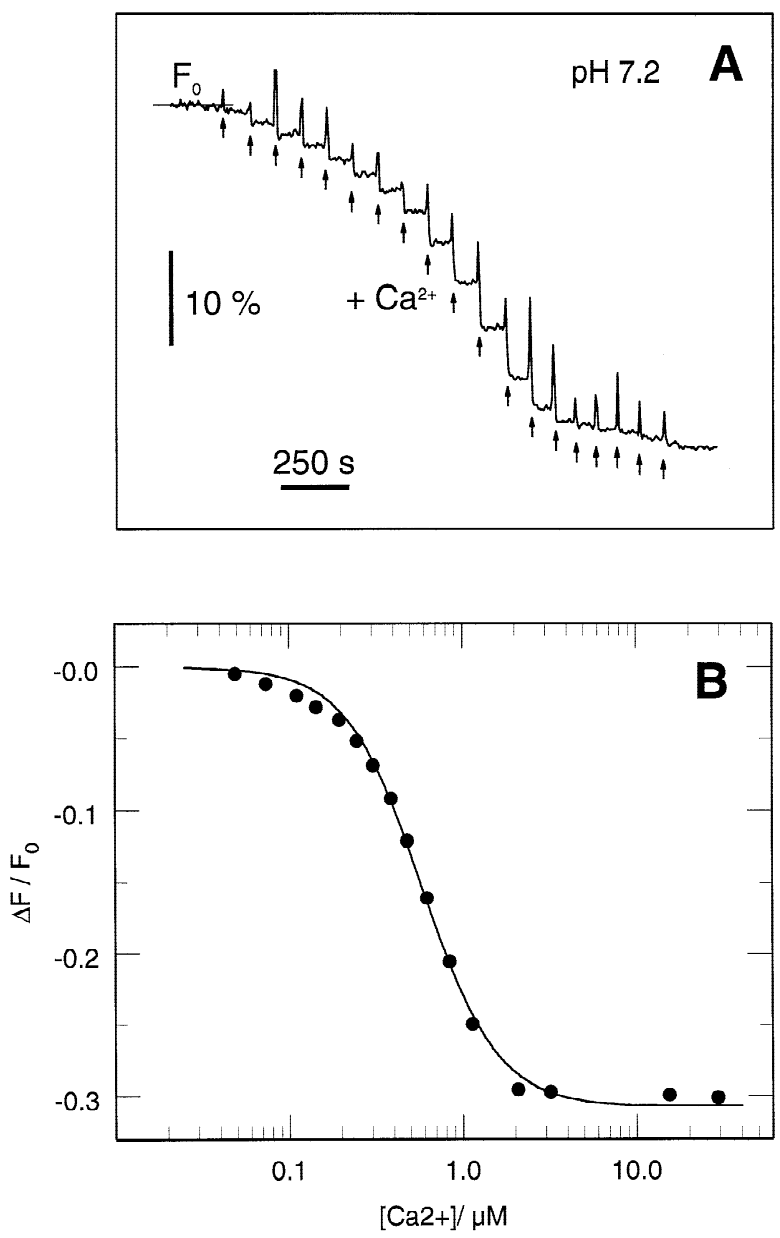

Fig. 4. Fluorescence changes induced by $\mathrm{Ca}^{2+}$ equilibrium titration experiments of the Ca-ATPase in its $\mathrm{E}_{1}$ conformation. (A) Representation of an original experiment. Buffer composition as given in Fig. $2 B$. The fluorescence intensity in buffer after addition of $0.1 \mathrm{~mm}$ EGTA was defined as $F_{0}$, relative to which the fluorescence changes were normalized: $\Delta F / F_{0}=\left(F-F_{0}\right) / F_{0}$. The precise $\mathrm{Ca}^{2+}$ concentration after each addition of $\mathrm{CaCl}_{2}$ (arrows) was determined by a FURA-2 experiment performed in parallel. $(B)$ The relative fluorescence changes, $\Delta F / F_{0}$, are plotted against $\mathrm{Ca}^{2+}$ concentration and the data could be fitted by a Hill function (Eq. 1) with a half saturating $\mathrm{Ca}^{2+}$ concentration, $K_{M}$, of $595 \mathrm{~nm}$ and a Hill coefficient, $n$, of 2 , which indicates a strictly cooperative binding of $2 \mathrm{Ca}^{2+}$ ions. This result is in good agreement with published data on the cytoplasmic binding affinity and supports the proposal that 2BITC detects the $\mathrm{Ca}^{2+}$ binding to the ion pump.

7.2, and $200 \mathrm{~nm}$ 2BITC, SR membranes $(18 \mu \mathrm{g} / \mathrm{ml})$ were added and equilbrated until a stable fluorescence level was obtained. Then BAPTA was added to a final concentration of $0.1 \mathrm{~mm}$ to remove nominally all $\mathrm{Ca}^{2+}$ ions bound to the ATPase which is reflected by an increase of the fluorescence intensity. Then aliquots of $\mathrm{CaCl}_{2}$ solutions were added and the fluorescence decrease recorded (Fig. 4A). In parallel, exactly the same experimental protocol was performed in a cuvette which contained in addition 333 nm FURA-2 as an optical indicator to determine the precise free $\mathrm{Ca}^{2+}$ concentrations in the range below $1 \mu \mathrm{M}$. The normalized fluorescence changes of the 2BITC signal, $\Delta F / F_{0} \equiv\left(F\left(E_{1}+\mathrm{Ca}^{2+}\right)-F\left(E_{1}\right)\right) / F\left(E_{1}\right)$, were plotted against the $\mathrm{Ca}^{2+}$ concentration (Fig. $4 B$ ) and fitted by a Hill function

$\frac{\Delta F}{F_{0}}=\left.\frac{\Delta F}{F_{0}}\right|_{\max } \times \frac{1}{1+\left(K_{M} /\left[\mathrm{Ca}^{2+}\right]\right)^{n}}$.

At $\mathrm{pH} 7.2$ (shown in Fig. $4 B$ ) the maximum fluorescence change, $\Delta F / F_{0 \max }$, was about $-31 \%$, the half-saturating $\mathrm{Ca}^{2+}$ concentration, $K_{M}$, was $600 \pm 20 \mathrm{nM}$, and the Hill coefficient, $n$, was $2( \pm 0.1)$. This finding supports the assumption that changes of 2BITC fluorescence reflect $\mathrm{Ca}^{2+}$ binding to the Ca-ATPase and that this process is electrogenic.

\section{Calcium Titration in State P-E $E_{2}$ of the SR-Ca-ATPase}

The effect of $\mathrm{Ca}^{2+}$ binding to the sites presented at the lumenal interface in the $\mathrm{P}-\mathrm{E}_{2}$ conformation of the $\mathrm{Ca}$ ATPase was investigated by the following experiments. To buffer containing $25 \mathrm{~mm}$ tricine, $50 \mathrm{mM} \mathrm{KCl}, 1 \mathrm{mM}$ $\mathrm{MgCl}_{2}, \mathrm{pH} 7.2$ and $200 \mathrm{~nm}$ 2BITC, SR membranes (18 $\mu \mathrm{g} / \mathrm{ml}$ ) were added followed by ATP to a final concentration of $1 \mathrm{~mm}$ and the suspension was equilibrated until a stable fluorescence intensity was obtained. According to measurements with a $\mathrm{Ca}^{2+}$-sensitive electrode under this conditon (in the absence of a chelator) the free $\mathrm{Ca}^{2+}$ concentration was $5 \pm 1 \mu \mathrm{M}$. Therefore it could be assumed that the proteins were preferentially in state $\mathrm{P}-\mathrm{E}_{2}$. By addition of various aliquots from $\mathrm{CaCl}_{2}$ stock solutions $(25 \mathrm{~mm}$ to $1.6 \mathrm{M})$ the ion concentration was increased up to $82 \mathrm{~mm}$ and the accompanying 2BITC fluorescence was recorded (Fig. 5A). Above $20 \mathrm{~mm}$ a beginning saturation of the fluorescence decrease began to be observed (Fig. 5B). Unfortunately, control experiments with pure lipid vesicles and with SR membranes inhibited thermally or by $0.5 \mu \mathrm{M}$ tharpsigargin before addition of ATP revealed that $\mathrm{Ca}^{2+}$ concentrations above $1 \mathrm{~mm}$ affected the 2BITC fluorescence intenstiy as demonstrated in Fig. $5 B$ (open circles). In the case of RH421 high $\mathrm{Ca}^{2+}$ concentrations did not affect the fluorescence intensity (Fig. 2B). A possible origin of this effect may be adsorption of the divalent ions on the membrane surface which generates an electrostatic interaction with the dye molecules. When the difference between the fluorescence changes of active and inhibited protein was determined, a significant fluorescence decrease remained (open squares in Fig. $5 B$ ). The remaining fluorescence decrease $\left(\Delta F /\left.F_{0}\right|_{\max }=-25 \%\right)$ indicated an electrogenic $\mathrm{Ca}^{2+}$ binding in state $\mathrm{P}-\mathrm{E}_{2}$. The difference signal can be approximated by the sum of two binding isotherms with 

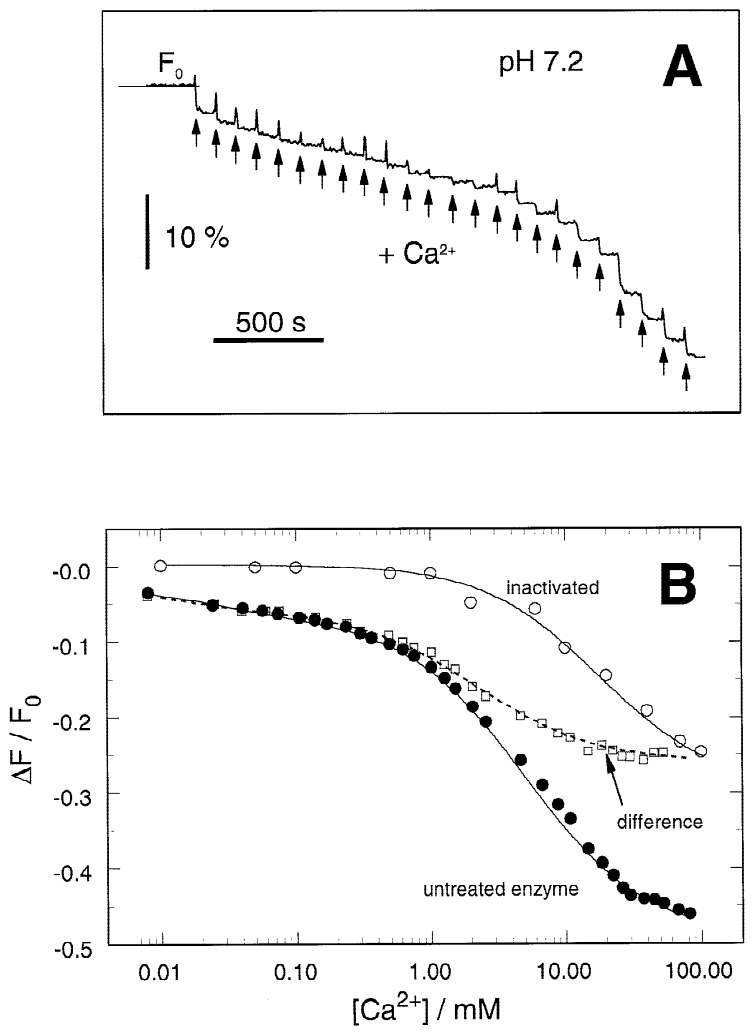

Fig. 5. Fluorescence changes induced by $\mathrm{Ca}^{2+}$ equilibrium titration experiments of the Ca-ATPase in its $\mathrm{P}^{-\mathrm{E}_{2}}$ conformation. (A) Representation of an original experiment. Buffer composition as given in Fig. $2 B$. The fluorescence intensity in buffer after addition of $1 \mathrm{~mm}$ ATP was defined as $F_{0}$. $(B)$ The relative fluorescence changes, $\Delta F / F_{0}$, are plotted against $\mathrm{Ca}^{2+}$ concentration. The filled circles represent two overlaid titration experiments with uninhibited enzyme. The data could be fitted by the sum of two binding isotherms (line). To determine the nonspecific effect of high $\mathrm{Ca}^{2+}$ concentrations $(>1 \mathrm{mM})$ on 2BITC in SR-membranes experiments similar to the one shown in panel $A$ were repeated with thermally inactivated SR membranes. The nonspecific effect of $\mathrm{Ca}^{2+}$ on 2BITC (open circles) could be fitted phenomenologically by a binding isotherm with a $K_{M}$ of $19 \mathrm{~mm}$. The difference between the experimental data (filled circles) and the binding isotherm was calculated and plotted (open squares). The resulting fluorescence decrease could be fitted by a sum of two binding isotherms (dashed line) with half saturation $\mathrm{Ca}^{2+}$ concentrations of $5 \mu \mathrm{M}$ and $2.2 \mathrm{~mm}$.

equilibrium dissociation constants of $5 \pm 1.2 \mu \mathrm{M}$ and $2 \pm$ $0.2 \mathrm{mM}$ at $\mathrm{pH} 7.2$ as shown in Fig. $5 B$ (dashed line).

\section{pH Dependence of $\mathrm{Ca}^{2+}$-binding Reactions}

Further experiments were performed to investigate the effect of $\mathrm{pH}$ on the fluorescence intensity of 2BITC and of the SR-Ca-ATPase which has been shown to transport $\mathrm{H}^{+}$ions as counter ion to $\mathrm{Ca}^{2+}$ (Yu et al., 1994). First we performed the standard experiment as shown in Fig. $2 D$, but varied $\mathrm{pH}$ between 6.2 and 8.0. The buffer compo- sition corresponded to that of Fig. $2 D$ with the exception of the chelator: $100 \mu \mathrm{M}$ EGTA was replaced by $100 \mu \mathrm{M}$ BAPTA, which is much less $\mathrm{pH}$ sensitive with respect to its affinity for $\mathrm{Ca}^{2+}$. The results are represented in Fig. 6, in which the fluorescence changes were normalized to the fluorescence intensity prior the first substrate addition (0.1 mM BAPTA). It can be seen that under buffer conditions in which the ion-binding sites were saturated with $\mathrm{Ca}^{2+}$ in $\mathrm{E}_{1}$ as well as in $\mathrm{P}-\mathrm{E}_{2}$, the fluorescence levels were not significantly different in buffers of $\mathrm{pH}$ between 6.2 and 8. This is a strong indication that 2BITC is not a $\mathrm{pH}$ indicator. Direct $\mathrm{pH}$ titration experiments with lipid vesicles and 2BITC confirmed that there were no significant changes of the fluorescence level in the range of pH5.5 to 8 (data not shown).

When the ion binding sites could be assumed to be virtually free of $\mathrm{Ca}^{2+}$ after addition of $0.1 \mathrm{~mm}$ BAPTA $\left(\left[\mathrm{Ca}^{2+}\right]<20 \mathrm{nM}\right.$ ) in state $\mathrm{E}_{1}$ and in state $\mathrm{P}-\mathrm{E}_{2}$ (in the presence of $\sim 30 \mu \mathrm{M} \mathrm{Ca}{ }^{2+}$ ) it could be observed that the fluorescence levels exhibited a distinct $\mathrm{pH}$ dependence. This effect can be assigned to an ion-pump specific process which has electrogenic components. On the basis of the findings of Yu et al. (1994) in reconstituted vesicles, it was a reasonable assumption to correlate the fluorescence changes with proton binding to the ion sites.

Therefore $\mathrm{pH}$ dependence of the two sensitive states of the Ca-ATPase, $\mathrm{E}_{1}$ and $\mathrm{P}-\mathrm{E}_{2}$, was investigated in a second step. In Fig. 7 the results of two series of experiments are shown. The fluorescence responses in conformation $\mathrm{E}_{1}$ were determined in standard buffers, in which the $\mathrm{pH}$ was adjusted by $\mathrm{HCl}$ or $\mathrm{KOH}$ to the indicated value. $200 \mathrm{~nm} 2 \mathrm{BITC}$ and SR membranes $(9 \mu \mathrm{g} / \mathrm{ml}$ protein) were added and equilibrated at $20^{\circ} \mathrm{C}$ until a stable fluorescence intensity was obtained. Then BAPTA was added to a final concentration of $0.1 \mathrm{~mm}$ and the fluorescence increase was monitored. Further addition of BAPTA did not change the fluorescence intensity.

The fluorescence increase was normalized to the level before addition of the chelator and plotted against buffer $\mathrm{pH}$. In Fig. $7 A$ the results of experiments with one preparation are shown (filled circles). Results of repetitions with different enzyme preparations did not vary significantly. The normalized fluorescence levels obtained in the $\mathrm{pH}$ range between 7 and 5.6 could be fitted by a Hill function with a $\mathrm{pK}$ of 5.9 and a Hill coefficient, $n$, of 1.6 (solid line in Fig. 7A). As a complementary experiment $\mathrm{pH}$ titrations were performed. After BAPTA addition at $\mathrm{pH} 8$ as described above, aliquots of $\mathrm{HCl}$ were added and the $\mathrm{pH}$ of the buffer reduced stepwise to 5.6. The fluorescence levels were detected, normalized and plotted against their corresponding $\mathrm{pH}$ values (Fig. $7 A$, open circles). The results of both experiments agreed well. The reduced $\Delta F /\left.F_{0}\right|_{\max }$ at $\mathrm{pH}>7$ is not understood so far.

To investigate the effect of $\mathrm{pH}$ on fluorescence in 


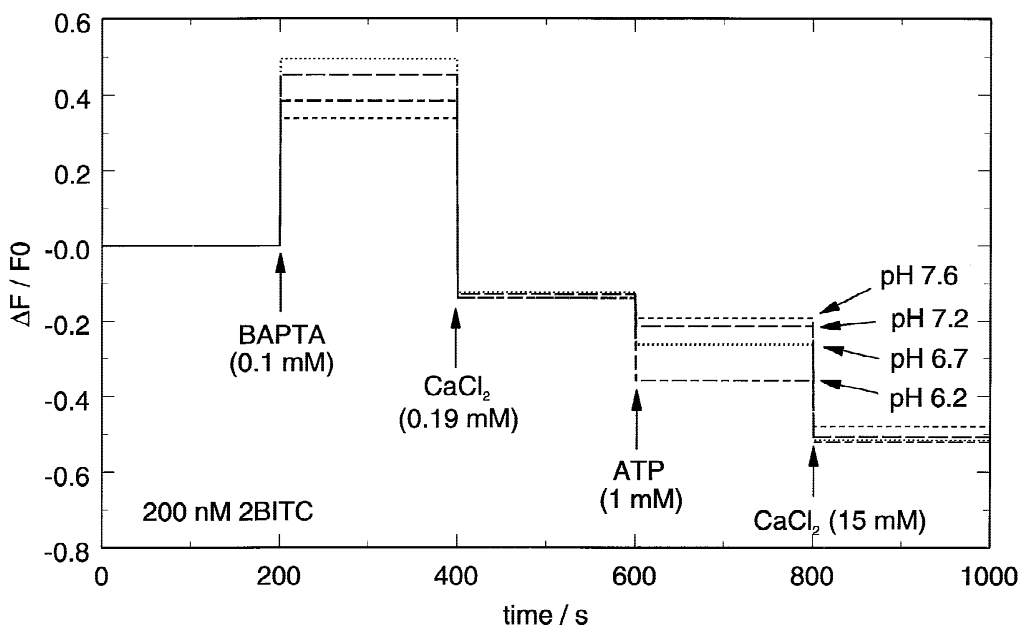

Fig. 6. Standard experiments performed in buffers of different $\mathrm{pH}$. Relative fluorescence changes were normalized to the intensity prior the addition of 0.1 mM BAPTA. It is obvious that in states in which binding sites were not occupied by (saturating) $\mathrm{Ca}^{2+}$ but were accessible to $\mathrm{H}^{+}$ions (states $\mathrm{E}_{1}$ and $\mathrm{P}-\mathrm{E}_{2}$ ) a significant effect of $\mathrm{pH}$ on the fluorescence was found. In state $\mathrm{P}-\mathrm{E}_{2}$ a monotonic fluorescence decrease with increase of $\mathrm{H}^{+}$concentration was observed. In state $\mathrm{E}_{1}$ a maximum effect on fluorescence intensity was found at $\mathrm{pH} 6.7$.

conformation $\mathrm{P}-\mathrm{E}_{2}$, experiments were performed in standard buffers in which the initial $\mathrm{pH}$ was adjusted to 8 with $\mathrm{KOH}$. After addition of $200 \mathrm{~nm}$ 2BITC, SR membranes $(9 \mu \mathrm{g} / \mathrm{ml}$ protein) and $1 \mathrm{mM} \mathrm{ATP}$, the cuvette was equilibrated at $20^{\circ} \mathrm{C}$ until a stable fluorescence intensity was obtained. Since no chelator was present the unbuffered $\mathrm{Ca}^{2+}$ concentration was about $1-5 \mu \mathrm{M}$. This fluorescence level was defined to be $F_{0}$. Then an aliquot of $\mathrm{HCl}$ was added, the fluorescence decrease to the new stationary level was monitored and then the $\mathrm{pH}$ was measured by a $\mathrm{pH}$ electrode. $\mathrm{pH}$ steps were performed in the range between 8 and 5.35. The fluorescence changes were normalized with respect to $F_{0}$ and plotted against the $\mathrm{pH}$ after addition of $\mathrm{HCl}$ (Fig. $7 B$ ). The $\mathrm{pH}$ dependence of $\Delta F /\left.F_{0}\right|_{\max }$ could be fitted by a simple binding isotherm with a $\mathrm{pK}$ below 5.5. The observation that the fluorescence did not change significantly above $\mathrm{pH} 7$ indicated that the fluorescence decrease in this $\mathrm{pH}$ range as shown in Fig. $7 A$ is not a nonspecific effect of the dye or the SR membranes.

Besides a direct effect of the $\mathrm{H}^{+}$concentration on 2BITC fluorescence, it could be shown that $\mathrm{pH}$ could also affect $\mathrm{Ca}^{2+}$ binding in state $\mathrm{E}_{1}$ on the cytoplasmic side of the ion pump. $\mathrm{Ca}^{2+}$ titration experiments as described above (Fig. 4) were repeated in buffers with a $\mathrm{pH}$ adjusted to a value between 6.15 and 7.6, and the halfsaturating $\mathrm{Ca}^{2+}$ concentration, $K_{M}$, was determined for each titration by a fit of the concentration dependence with the Hill equation (Eq. 1). The results are shown in Fig. 8. Significantly higher $\mathrm{Ca}^{2+}$ concentrations were necessary at low $\mathrm{pH}$ to cause the same effect as in high $\mathrm{pH}$ buffers. The dashed line drawn in Fig. 8 was simulated under the assumption that $2 \mathrm{H}^{+}$ions can bind to the twofold negatively charged ion sites (Yu et al., 1994), and thus decrease the affinity of $\mathrm{Ca}^{2+}$ binding. An apparent $\mathrm{pK}$ was determined to be 7.2 from the curve fitting the experimental data. The proton-independent equilibrium dissociation constant for $\mathrm{Ca}^{2+}$ was estimated to be

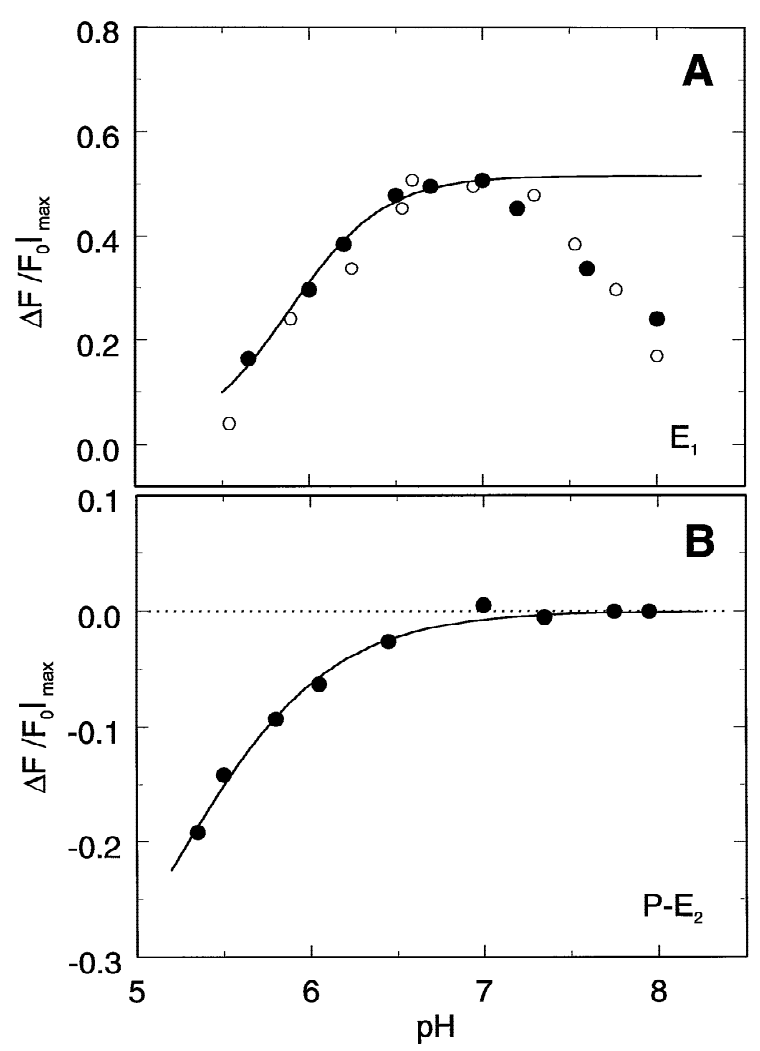

Fig. $7 \mathrm{pH}$ titration of the SR-Ca-ATPase in conformation $\mathrm{E}_{1}$ and $\mathrm{P}-\mathrm{E}_{2}$ as detected by $2 \mathrm{BITC}$ fluorescence changes. $(A)$ In $\mathrm{E}_{1}$ the normalized fluorescence changes $\Delta F /\left.F_{0}\right|_{\max }$ were obtained by addition of BAPTA to remove all $\mathrm{Ca}^{2+}$ from the ion pumps. The $\mathrm{pH}$ was maintained in the buffer by appropriate additions of $\mathrm{HCl}$ or $\mathrm{KOH}$. The line represents the fit of a Hill function (Eq. 1) to the data between $\mathrm{pH} 5.6$ and 7 with a $K_{M}$ of $1.26 \mu \mathrm{M}$ (or pK 5.9) and $n=1.6$. (B) In P-E $\mathrm{E}_{2}$ the enzyme was 'locked' initially in this state by the presence of $\sim 5 \mu \mathrm{M} \mathrm{Ca}^{2+}$ and $1 \mathrm{mM}$ ATP. Addition of various aliquots of $\mathrm{HCl}$ reduced the buffer $\mathrm{pH}$ and the corresponding fluorescence change was monitored. The line represents a binding isotherm with a $K_{M}$ below $3.2 \mu \mathrm{M}(\mathrm{pK}<5.5)$. 


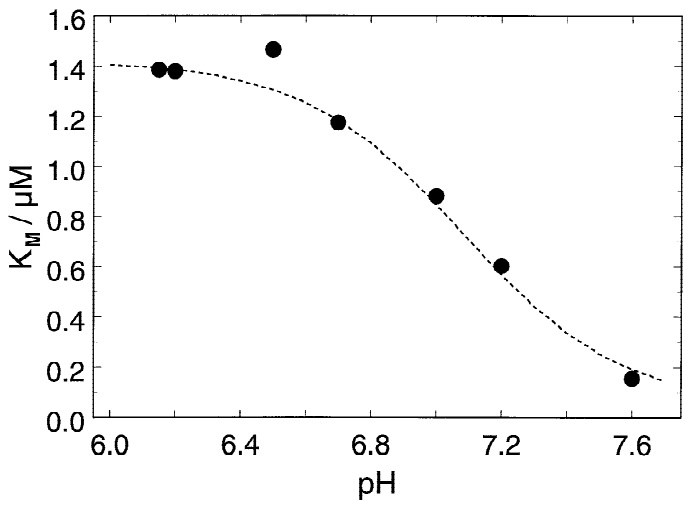

Fig. 8. $\mathrm{pH}$ dependence of cytoplasmic $\mathrm{Ca}^{2+}$ binding in terms of the half-saturating $\mathrm{Ca}^{2+}$ concentration, $K_{M}$, determined from $\mathrm{Ca}^{2+}$ titration experiments at various $\mathrm{pH}$ as shown in Fig. 4 at $\mathrm{pH}$ 7.2. The dashed line corresponds to a competitive binding of two protons with an apparent pK of 7.1 to the negatively charged ion binding sites (see text).

in the order of $50 \mathrm{~nm}$. It was increased to about $1450 \mathrm{nM}$ at saturating $\mathrm{H}^{+}$concentrations.

\section{Discussion}

The experiments presented with SR membrane preparations and the styryl dye 2BITC demonstrate that it is possible to investigate electrogenic events in the SR-CaATPase despite the high native leakage of these membranes which prevents direct electrophysiological measurements. Most known ion pumps are 'electrogenic', i.e., they translocate net charge across the membrane (Läuger, 1991). This definition has been extended to partial reactions of the pump cycle. Electrogenicity is defined there as a property of reaction steps in which charge is moved through (part of) the protein/membrane with a low dielectric constant. The electrogenic contributions of such reaction steps may be described in terms of dielectric coefficients, and the sum of the dielectric coefficients of all reaction steps in the pump cycle equals the net charges translocated across the membrane (Läuger \& Apell, 1986, Läuger, 1991). Styryl dyes, especially RH421, were used with great success to investigate Na,K-ATPase-containing membrane preparations (Klodos \& Forbush, 1988, Stürmer et al., 1991, Pratap et al., 1993; Heyse et al., 1994, Fedosova, Cornelius \& Klodos, 1995; Kane et al., 1995; Apell et al., 1996; Clarke et al., 1998). Significant fluorescence changes have been observed in all partial reactions which contain electrogenic reaction steps.

$\mathrm{Na}, \mathrm{K}-\mathrm{ATPase}$-containing membrane fragments are open structures in which both faces of the membrane are accessible to the same buffer and therefore are electrically short circuited. The observed changes of the fluorescent dye may not be generated by transmembrane po- tentials but by changes of local electrical fields mainly on the basis of the mechanism of electrochromy (Bühler et al., 1991; Grinvald et al., 1982). Therefore this principle should also be applicable for SR membranes. Experiments using the styryl dye RH421 turned out to detect some fluorescence changes induced by $\mathrm{Ca}^{2+}$ binding and release steps, however, the changes were small and therefore rather sensitive to nonspecific drift effects of the fluorescence intensity (Fig. 2B). From previous investigations it was already known that various styryl dyes differ up to a factor of ten in their fluorescence response when applied to the same partial reactions of the Na,K-ATPase. Therefore, a variety of analogous styryl dyes was tested for their substrate-dependent response with the Na,K-ATPase and SR-Ca-ATPase (manuscript in preparation), and the dye 2BITC (Fig. $2 C)$ was found to be an excellent candidate for studies of electrogenic partial reactions of the Ca-ATPase. According to the physical mechanism of RH421, which is same for 2BITC due to the analogous chemical structure (Fig. 2C), a fluorescence decrease is caused by an increased positive charge within the membrane dielectric, a fluorescence increase by an increased negative (or decreased positive) charge respectively.

The investigation of the mechanism of 2BITC is still under progress. So far it is justified to assume that it functions in the same way as RH421 does since its voltage-dependent spectral properties are in good agreement with those of RH421 (manuscript in preparation). However, a flip-flop of 2BITC molecules between both lipid layers of the microsomal membrane may not yet be excluded. Such a permeation of dye molecules to the inner hemileaflet of the microsomal membrane could contribute to the differences of the fluorescence responses between 2BITC and the completely impermeable RH421.

A standard experiment was defined by a sequence of substrate additions with respect to the pump cycle of the Ca-ATPase (Fig. 1). Under the chosen substrate conditions (Fig. $2 B$ and $D$ ) the following stationary states were maintained: $\mathrm{Ca}_{\mathrm{x}} \mathrm{E}_{1}(\mathrm{x}=1-2), \mathrm{E}_{1}, \mathrm{Ca}_{2} \mathrm{E}_{1}, \mathrm{P}-\mathrm{E}_{2}, \mathrm{P}-\mathrm{E}_{2} \mathrm{Ca}_{2}$. The changes of the fluorescence intensity upon substrate additions indicate that especially ion binding or release steps contribute to the electrogenicity of the Ca-ATPase. The ATP-induced conformational transition, $\mathrm{E}_{1} \rightarrow \mathrm{E}_{2}$, is accompanied only by a small alteration of the fluorescence $\left(\Delta F / F_{0} \leqslant 10 \%\right)$. The absence of comparable fluorescence changes in control experiments with proteinfree lipid vesicles or with enzyme inhibited thermally or by tharpsigargin, showed that the observed changes were produced by substrate-specific partial reactions. The effect of high $\mathrm{Ca}^{2+}$ concentrations $(>1 \mathrm{mM})$ will be discussed below.

Although it is not possible to assign dielectric coefficients to the observed reaction steps on the basis of the data presented, it can be concluded that ion movements 
between the aqueous phases and the binding sites are the main electrogenic events in the transport of $\mathrm{Ca}^{2+}$ by the SR-Ca-ATPase.

\section{CALCIUM-INDUCED EFFECTS}

The dependence of the fluorescence decrease as a function of the $\mathrm{Ca}^{2+}$ concentration in the $\mathrm{E}_{1}$ and in the $\mathrm{P}-\mathrm{E}_{2}$ conformation of the Ca-ATPase (Figs. 4 and 5) is in agreement with previously published findings and supports the interpretation that $2 \mathrm{BITC}$ reports specific protein functions. $\mathrm{Ca}^{2+}$ titration in state $\mathrm{E}_{1}$ resulted in a fluorescence decrease that could be described by cooperative $\mathrm{Ca}^{2+}$ binding which can be fitted by a single Hill curve with an half-saturating concentration, $K_{M}$, of $600 \pm$ $50 \mathrm{~nm}$ and a Hill coefficient, $n$, of 2 (Fig. $4 B$ ). This result is in agreement with data obtained by binding radioactive $\mathrm{Ca}^{2+}$ ions (Inesi et al., 1980) with $1 / K_{\text {app }}=440 \mathrm{nM}$ and $n=1.82$. The effect of $\mathrm{Ca}^{2+}$ binding on the intrinsic tryptophan fluorescence has been studied under various $\mathrm{Mg}^{2+}$ concentrations and $\mathrm{pH}$, and under comparable conditions ( $1 \mathrm{mM} \mathrm{Mg}^{2+}, \mathrm{pH}$ 7) half-saturating concentrations of $K_{M}=730 \mathrm{nM}(n=1.6)$ (Forge, Mintz \& Guillain, 1993) and $400 \mu \mathrm{M}$ (Dupont, 1976) were published.

Upon addition of ATP a sequence of reaction steps occurs spontaneously: enzyme phosphorylation and ion occlusion, conformational transition to $\mathrm{E}_{2}$, and release of $\mathrm{Ca}^{2+}$ to the lumenal side of the ion pump (Fig. 1). The small fluorescence decrease in this partial reaction indicated that no dramatic change of net charge within the protein dielectric could be detected by the fluorescent dye (Figs. $2 D$ and 6). In a standard experiment with thermally inactivated membrane preparations addition of ATP caused a small fluorescence increase of $<+5 \%$ (not shown) which was comparable to that in the case of tharpsigargin-inhibited enzyme (Fig. $3 A$ ). Due to the fact that the vesicular membrane preparation is very leaky and that the addition of A23187 and FCCP, which short-circuits the membranes for $\mathrm{Ca}^{2+}$ (Yu et al., 1993), did not alter the fluorescence levels in the standard experiment significantly, we may assume that the final $\mathrm{Ca}^{2+}$ concentration is the same on both sides of the membrane in the case of the slow equilibrium-titration experiments. In the standard experiment enzyme phosphorylation was performed in the presence of about $50 \mu \mathrm{M}$ free $\mathrm{Ca}^{2+}$, therefore in state $\mathrm{P}-\mathrm{E}_{2}$ at least one ion-binding site should be free of $\mathrm{Ca}^{2+}$ because of the strongly reduced affinity of the sites. Taking all these facts into account the observed small fluorescence decrease in the partial reaction $\mathrm{Ca}_{2} \mathrm{E}_{1} \rightarrow \mathrm{P}-\mathrm{E}_{2}$ (or $\mathrm{P}-\mathrm{E}_{2} \mathrm{Ca}$ ) provides a strong constraint for modeling the electrogenicity of the transport mechanism (see below).

To titrate the $\mathrm{Ca}^{2+}$-binding sites in state $\mathrm{P}-\mathrm{E}_{2}$, the ion concentrations had to be increased up to $100 \mathrm{~mm}$ (Fig. 5).
$\mathrm{Ca}^{2+}$ concentrations above $1 \mathrm{~mm}$ produced a significant artifact with the dye 2BITC, as could be shown in control experiments with lipid vesicles and with membrane preparations inactivated by tharpsigargin or by hightemperature incubation (Fig. 5B). The specific effect of $\mathrm{Ca}^{2+}$ binding to the ion pump on the fluorescence intensity could be determined only by subtraction of the nonspecific fluorescence decrease from the total fluorescence signal (Fig. 5B). Therefore, the obtained binding affinities of the enzyme in $\mathrm{P}-\mathrm{E}_{2}$ are less precise than all other properties of the SR-Ca-ATPase presented in this study. Two distinct equilibrium dissociation constants for $\mathrm{Ca}^{2+}, 5 \mu \mathrm{M}$ and $2.2 \mathrm{mM}$, have been determined (Fig. $5 B$ ). These results may be compared with previously published data. As discussed by Mintz and Guillan (1997), it is rather difficult to investigate the properties of the lumenal calcium sites. In the case of ATP synthesis (by reversal of the SR-Ca-ATPase) an apparent dissociation constant between $300 \mu \mathrm{M}$ and $1 \mathrm{~mm}$ was estimated (Prager et al., 1979; de Meis, Martins \& Alves, 1980). Inesi and de Meis (1989) compiled from various sources rate constants for $\mathrm{Ca}^{2+}$ binding and release reactions in the $\mathrm{P}-\mathrm{E}_{2}$ state, from which equilibrium constants of $7 \mathrm{~mm}$ and $33 \mathrm{~mm}$ can be calculated. Considering the methodological uncertainties these values and our findings are in fair agreement. If in future investigations the problem of the $\mathrm{Ca}^{2+}$-induced dye artifact can be solved, the method presented in this paper may provide accurate estimates of the lumenal $\mathrm{Ca}^{2+}$ binding affinities.

\section{THARPSIGARGIN-INDUCED EFFECTS}

Experiments performed either by addition of or in the presence of tharpsigargin showed that the inhibitor led to a protein state with the highest fluorescence level detected, which was slightly, but not significantly, higher than that of state $\mathrm{E}_{1}$ (Fig. 3). This level indicates the lowest amount of positive charge within the ion pumps. If the small effects of substrate additions $(<5 \%)$ in standard experiments with tharpsigargin-inhibited enzyme (Fig. 3A) are assigned to nonspecific interactions between the charged substrates and the dye then this high fluorescence level could indicate an inhibited state of the Ca-ATPase which is related to state $\mathrm{E}_{1}$ with empty ion sites blocked for $\mathrm{Ca}^{2+}$ binding. This interpretation was suggested by previous studies (see Inesi \& Sagara, 1992), in which it was demonstrated that tharpsigargin forces the enzyme into a 'dead end complex' and inhibits $\mathrm{Ca}^{2+}$ binding in the ion sites as well as ATP binding in the nucleotide site.

\section{pH-INDUCED EFFECTS}

The effect of protons on the action of the SR-Ca-ATPase has been investigated for a number of years. It has been 


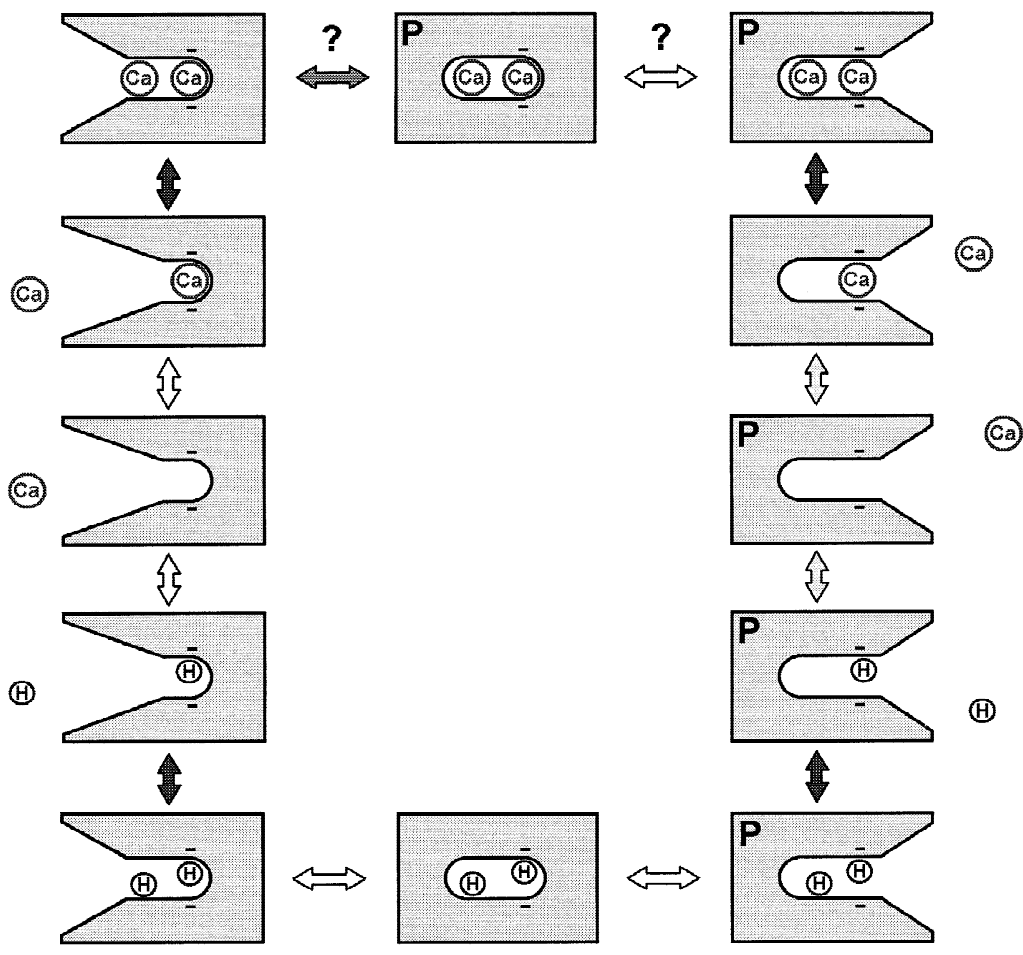

Fig. 9. Electrostatic model of the SR-Ca-ATPase on the basis of the model of Yu et al. (1994). The jaw-like widened access to binding sites symbolize a low electric field condition which does not contribute significantly to an electrogenic reaction step. The darker the arrows between states the more pronounced is the suggested electrogenicity. Question marks indicate possible candidates for electrogenic steps which could not be resolved experimentally so far. We would like to note that the drawing is meant only schematically and does not propose structural concepts. found that $\mathrm{H}^{+}$ions affect $\mathrm{Ca}^{2+}$ binding (Forge et al., 1993) and that $\mathrm{H}^{+}$ions are transferred as counterions by the ion pump from lumen to cytoplasm (Madeira, 1978; Chiesi \& Inesi, 1980) and out of the internal volume of reconstituted vesicles (Yu et al., 1994). The results of experiments on $\mathrm{pH}$ effects presented in this paper are consistent with the interpretation that $\mathrm{H}^{+}$ions are able to bind in or at least so close to the $\mathrm{Ca}^{2+}$ sites that they mutually exclude each other within the binding moiety.This view is supported by the findings that (i) $\mathrm{H}^{+}$ions produce fluorescence decreases similar to those of $\mathrm{Ca}^{2+}$ when binding was promoted by increasing concentrations, (ii) $\mathrm{pH}$-induced effects on 2BITC are found only under conditions when the binding sites are accessible, i.e., not occupied by saturating $\mathrm{Ca}^{2+}$ concentrations, and (iii) the binding affinity for $\mathrm{Ca}^{2+}$ can be affected in a way that could be predicted by competition with $\mathrm{H}^{+}$ions for the same sites.

Not understood so far is the fluorescence decrease observed in conformation $\mathrm{E}_{1}$ at $\mathrm{pH}$ values above 7 (Fig. $7 A$ ). This effect was not observed in state $\mathrm{P}-\mathrm{E}_{2}$; therefore, a nonspecific dye artifact may be excluded. The decrease of the fluoresce intensity suggests either an import of positive charge within the protein dielectric or the disappearance of negative charge. Since BAPTA has been used as chelator, a loss of $\mathrm{Ca}^{2+}$-binding capacity at high $\mathrm{pH}$ and therefore an increase of free $\mathrm{Ca}^{2+}$ concentration can be excluded. Possible explanations could be increased $\mathrm{Mg}^{2+}$ binding when the $\mathrm{H}^{+}$concentration is low enough, or $\mathrm{pH}$-induced conformational rearrange- ments of protein structure in which dipoles created by the amino acids could orient in a such a way that a net positive potential is generated inside the transmembrane domains and is detected by the dye. This finding will be investigated in more detail in future investigations.

\section{Refinement of a Mechanistic Model}

In summary it can be stated that all major fluorescence changes were associated with partial reactions in which ions were moved into or out of the binding sites. On the basis of the presented experimental evidence it is a reasonable assumption that the reactions $\mathrm{E}_{1}+2 \mathrm{Ca}^{2+} \rightleftharpoons$ $\mathrm{Ca}_{2} \mathrm{E}_{2}$ (as well as $\mathrm{E}_{1}+2 \mathrm{H}^{+} \rightleftharpoons \mathrm{H}_{2} \mathrm{E}_{2}$ ) and $\mathrm{P}-\mathrm{E}_{2}+2 \mathrm{Ca}^{2+}$ $\rightleftharpoons \mathrm{P}-\mathrm{E}_{2} \mathrm{Ca}_{2}\left(\mathrm{P}-\mathrm{E}_{2}+2 \mathrm{H}^{+} \rightleftharpoons \mathrm{P}-\mathrm{E}_{2} \mathrm{H}_{2}\right)$ are electrogenic. In Fig. 9 an electrostatic model is presented which is based on the $\mathrm{H}^{+} / \mathrm{Ca}^{2+}$ exchange model of the Ca-ATPase as published by $\mathrm{Yu}$ et al. (1994).

The observation that the concentration dependence of the electrogenic contribution for the reaction $\mathrm{E}_{1}+2$ $\mathrm{Ca}^{2+} \rightleftharpoons \mathrm{Ca}_{2} \mathrm{E}_{2}$ can be described by a single cooperative binding process may be understood on the basis of the strictly sequential binding of $\mathrm{Ca}^{2+}$ binding (Inesi, 1987; Inesi, Sumbilla \& Kirtley, 1990) in analogy to the " jawclosing" model of cooperative $\mathrm{Ca}^{2+}$ binding by the pump (Tanford, Reynolds \& Johnson, 1987). If binding of the first $\mathrm{Ca}^{2+}$ ion takes place through a water-filled vestibule (with a high dielectric constant, and therefore not electrogenically), and the subsequent "jaw-closing" creates 
the second site to which a second $\mathrm{Ca}^{2+}$ binds with very high affinity (Inesi \& de Meis, 1989), then only the " "jaw-closing" and the second $\mathrm{Ca}^{2+}$ binding will contribute to the electrogenicity of this partial reaction, which is then reported by the fluorescent probe. An alternative explanation to this single-file process has been recently proposed by Menguy et al. (1998). They present evidence that the cytoplasmic loop between transmembrane segments M6 and M7, with its negatively charged amino acids is involved in binding of the first $\mathrm{Ca}^{2+}$ ion and, upon interaction with the first $\mathrm{Ca}^{2+}$, access to the second binding site within the transmembrane domains of the protein becomes possible. This model is able to explain also the observed concentration dependence of $\mathrm{Ca}^{2+}$ binding.

The transition $\mathrm{Ca}_{2} \mathrm{E}_{1} \rightarrow \mathrm{P}-\mathrm{E}_{2}$ seems to generate only a minor contribution to electrogenicity (Fig. 2D). This observation is significantly different from the observation of the ATP-induced fluorescence change in the case of Na,K-ATPase (Fig. $2 A$ ) where this reaction step produces the major electrogenic effect in the partial reactions covered by the standard experiment. The fluorescence increase in the order of $80-100 \%$ could be explained by the presence of two uncompensated negative charges of the ion-binding sites within the protein dielectric of the Na,K-ATPase (Heyse et al., 1994). Since lumenal $\mathrm{Ca}^{2+}$ binding to the $\mathrm{Ca}$-ATPase was found to be electrogenic (Fig. 5B), it may be suggested that the transient $\mathrm{Ca}^{2+}$ occlusion (and/or the conformation transition) is accompanied by an electrogenic effect which would produce to a fluorescence level similar to that of state $\mathrm{P}-\mathrm{E}_{2} \mathrm{Ca}_{2}$ which cannot be resolved in the presented equilibrium titration experiments. These apparently differing electrostatic conditions of the $\mathrm{P}-\mathrm{E}_{2}$ states of the SR$\mathrm{Ca}-\mathrm{ATPase}$ and the Na,K-ATPase will be subject of further studies.

When lumenal $\mathrm{Ca}^{2+}$ binding was analyzed, a two step process was found in which binding of the first $\mathrm{Ca}^{2+}$ with higher affinity produced a smaller fluorescence decrease than binding of the second (Fig. 5B). This could be explained by the assumption that the site closer to the aqueous phase is more negatively charged than the inner site and therefore more attractive to $\mathrm{Ca}^{2+}$ ions. Binding of a second $\mathrm{Ca}^{2+}$ would include a single file process in which the first ion bound is pushed into the second site, which is placed deeper in the protein dielectric, to make way for the second ion at the outer, negatively charged site. This process would be expected to cause a stronger electrogenicity with a more pronounced fluorescence decrease than is observed.

Similar arguments would hold for $\mathrm{H}^{+}$binding to the sites. Interaction of additional $\mathrm{H}^{+}$with negatively charged amino acids in the binding moiety as proposed by $\mathrm{Yu}$ et al. (1994) might also occur. If the pK of the side groups is high enough, $\mathrm{P}-\mathrm{E}_{2}$ may actually be a state in which $2 \mathrm{H}^{+}$are already bound to negative charges close to the mouth of the 'access channel.' In Fig. 9 only those $\mathrm{H}^{+}$were plotted which are transported. The locations of the protons in state $\mathrm{P}-\mathrm{E}_{2} \mathrm{H}_{2}$ was assumed to account for the observed single binding isotherm in Fig. $7 B$. Due to the restricted $\mathrm{pH}$ range covered by the experiments this detail is purely speculative.

In this first approach we were able to demonstrate that an experimental technique previously applied to the $\mathrm{Na}, \mathrm{K}-\mathrm{ATPase}$ can be extended to the SR-Ca-ATPase with an analogue dye and that it allowed the determination of electrogenic partial reactions in agreement with the recently published stoichiometry and operational mode of the ion pump.

The authors would like to thank E. Ströbele and P. Koufen for helpful discussions, Christine Peinelt for technical assistance, and Dr. J. Breed for a critical reading of the manuscript. The styryl dye 2BITC was a gift from Prof. H.-D. Martin, University of Düsseldorf. This work was financially supported by the Deutsche Forschungsgemeinschaft (Sonderforschungsbereich 156).

\section{References}

Andersen, J.P. 1989. Monomer-oligomer equilibrium of sarcoplasmatic reticulum Ca-ATPase and the role of subunit interaction in the $\mathrm{Ca}^{2+}$ pump mechanism. Biochim. Biophys. Acta 988:47-72

Apell, H.-J. 1997. Kinetic and energetic aspects of the $\mathrm{Na}^{+} / \mathrm{K}^{+}$Transport cycle steps. Ann. N.Y. Acad. Sci. 834:221-230

Apell, H.-J., Bersch B. 1987. Oxonol VI as an optical indicator for membrane potentials in lipid vesicles. Biochim. Biophys. Acta 903:480-494.

Apell, H.-J., Roudna, M., Corrie, J.E.T., Trentham, D.R. 1996. Kinetics of the phosphorylation of Na,K-ATPase by inorganic phosphate detected by a fluorescence method. Biochemistry 35:10922-10930

Birmes, M. 1995. Neuartige membranpotentialsensitive Fluoreszenzfarbstoffe mit Styrylpyridiniumchromophor. Ph.D. thesis, University of Düsseldorf, Germany, pp. 1-248

Bühler, R., Stürmer, W., Apell, H.-J., Läuger, P. 1991. Charge translocation by the Na,K-pump: I. Kinetics of local field changes studied by time-resolved fluorescence measurements. J. Membrane Biol. 121:141-161

Chiesi, M., Inesi, G. 1980. Adenosine 5'-triphosphate dependent fluxes of manganese and hydrogen ions in sarcoplasmic reticulum vesicles. Biochemistry 19:2912-2918

Clarke, R., Kane, D.J., Apell, H.-J., Roudna, M., Bamberg, E. 1998. Kinetics of $\mathrm{Na}^{+}$dependent conformational changes of rabbit kidney $\mathrm{Na}^{+}, \mathrm{K}^{+}$-ATPase. Biophys. J. 75:1340-1353

de Meis, L. 1985. Role of water in processes of energy transduction: $\mathrm{Ca}^{2+}$-transport ATPase and inorganic pyrophosphatase. Biochem. Soc. Sympos. 50:97-125

de Meis, L., Inesi, G. 1992. Functional evidence of a transmembrane channel within the $\mathrm{Ca}^{2+}$ transport ATPase of sarcoplasmic reticulum FEBS Lett. 299:33-35

de Meis, L., Martins, O.B., Alves, E.W. 1980. Role of water, hydrogen ion and temperature on the synthesis of adenosine triphosphate by the sarcoplasmatic reticulum adenosine triphosphatase in the absence of a calcium ion gradient. Biochemistry 19:4252-4261

Dupont, Y. 1976. Fluorescence studies of the Sarcoplasmatic Reticulum. Biochim. Biophys. Res. Comm. 71:544-549

Fedosova, N.U., Cornelius, F., Klodos, I. 1995. Fluorescent styryl dyes 
as probes for Na,K-ATPase reaction mechanism: Significance of the charge of the hydrophobic moiety of RH dyes. Biochemistry 34:16806-16814

Forge, C., Mintz, E., Guillain, F. 1993. $\mathrm{Ca}^{2+}$-binding to sarcoplasmatic reticulum ATPase revisited. J. Biol. Chem. 268:10953-10960

Grinvald, A., Hildesheimer, R., Farber, I., Anglister, L. 1982. Improved fluorescence probes for the measurement of rapid changes in membrane potential. Biophys. J. 39:301-308

Grynkiewicz, G., Poenie, M., Tsien, R.Y. 1985. A new generation of $\mathrm{Ca}^{2+}$ indicators with greatly improved fluorescence properties. $J$. Biol. Chem. 260:3440-3450

Hasselbach, W., Oetliker, H. 1983. Energetics and electrogenicity of the sarcoplasmatic reticulum calcium pump. Annu. Rev. Physiol. 45:325-339

Heilmann, C., Brdiczka, D., Nickel, E., Pette, D. 1977. ATPase activities, $\mathrm{Ca}^{2+}$ transport and phosphoprotein formation in sarcoplasmatic reticulum subfractions of fast and slow rabbit muscles. Eur. J. Biochem. 81:211-222

Heyse, S., Wuddel, I., Apell, H.-J., Stürmer, W. 1994. Partial reactions of the Na,K-ATPase: Determination of rate constants. J. Gen. Physiol. 104:197-240

Inesi, G. 1985. Mechanism of calcium transport. Annu. Rev. Physiol. 47:573-601

Inesi, G. 1987. Sequential mechanism of calcium binding and translocation in sarcoplasmatic reticulum adenosine triphosphatase. $J$. Biol. Chem. 262:16338-16342

Inesi, G., de Meis, L. 1989. Regulation of steady state filling in sarcoplasmatic reticulum. Roles of back-inhibition, leakage, and slippage of the calcium pump. J. Biol. Chem. 264:5929-5936

Inesi, G., Sumbilla, C., Kirtley, M.E. 1990. Relationship of molecular structure and function in the $\mathrm{Ca}^{2+}$ transport ATPase. Physiol. Rev. 70:749-760

Inesi, G., Kurzmack, M., Coan, C., Lewis, D.E. 1980. Cooperative calcium binding and ATPase activation in sarcoplasmatic reticulum vesicles. J. Biol. Chem. 255:3025-3031

Inesi, G., Sagara, Y. 1992. Tharpsigargin, a high affinity and global inhibitor of intracellular $\mathrm{Ca}^{2+}$ transport ATPases. Arch. Biochem. Biophys. 298:313-317

Kane, D.J., Fendler, K., Grell, E., Bamberg, E., Taniguchi, K., Froehlich, J.P., Clarke, R.J. 1997. Stopped-flow kinetic investigations of the conformational changes of pig kidney $\mathrm{Na}^{+}, \mathrm{K}^{+}$-ATPase. Biochemistry 36:13406-13420

Klodos, I., Forbush III, B. 1988. Rapid conformational changes of the $\mathrm{Na} / \mathrm{K}^{+}$pump revealed by a fluorescent dye, RH 160. J. Gen. Physiol. 92:46a

Läuger, P. 1991. Electrogenic Ion Pumps. pp. 226-251. Sinauer, Sunderland, MA

Läuger, P., Apell, H.-J. 1986. A microscopic model for the currentvoltage behaviour of the Na,K-pump. Eur. Biophys. J. 13:309-321

Loew, L.M., Scully, S., Simpson, L., Waggoner, A.S. 1979. Evidence for a charge-shift electrochromic mechanism in a probe of membrane potential. Nature 281:497-499

Madeira, V.M.C. 1978. Proton gradient formation during transport of $\mathrm{Ca}^{2+}$ by sarcoplasmic reticulum. Arch. Biochem. Biophys. 185:316325

Markwell, M.A.K., Haas, S.M., Bieber, L.L., Tolbert, N.E. 1978. A modification of the lowry procedure to simlify protein determina- tion in membrane and lipoprotein samples. Analyt. Biochem. 87:206-210

Menguy, T., Corre, F., Boneau, L., Dechamps, S., Møller, J.V., Champeil, P., le Maire, M., Falson, P. 1998. The cytoplasmic loop located between transmembrane segments 6 and 7 controls activation by $\mathrm{Ca}^{2+}$ of sarcoplasmatic reticulum $\mathrm{Ca}^{2+}$-ATPase. J. Biol. Chem. 237:20134-20143

Mintz, E., Guillain, F. 1997. $\mathrm{Ca}^{2+}$ transport by the sarcoplasmatic reticulum ATPase. Biochim. Biophys. Acta 1318:52-70

Prager, R., Punzengruber, C., Kolassa, N., Winkler, F., Suko, J. 1979. Ionized and bound calcium inside isolated sarcoplasmatic reticulum of skeletal muscle and its significance in phosphorylation of adenosine triphosphatase by orthophosphate. Eur. J. Biochem. 97:239_ 250

Pratap, P., Palit, A., Grassi-Nemeth, E., Robinson, J.D. 1996. Kinetics of conformational changes associated with potassium binding to and release from $\mathrm{Na}^{+} / \mathrm{K}^{+}$-ATPase. Biochim. Biophys. Acta 1285: 203-211

Sagara, Y., Inesi, G. 1992. J. Biol. Chem. 266:13503-13506

Schefer, U., Aumann, D., Pretsch, E., Oesch, U., Simon, W. 1986. Neutral carrier based $\mathrm{Ca}^{2+}$-selective electrode with detection limit in the sub-nanomolar range. Anal. Chem. 272:13270-13274

Schwartz, A., Nagano, K., Nakao, M., Lindenmayer, G.E., Allen, J.C. 1971. The sodium- and potassium-activated adenosine triphosphatase system. Methods Pharmacol. 1:361-388

Stürmer, W., Apell, H.-J. 1992. Fluorescence study on cardiac glycoside binding to the $\mathrm{Na}, \mathrm{K}$-pump: Ouabain binding is associated with movement of electrical charge. FEBS Lett. 300:1-4

Stürmer, W., Bühler, R., Apell, H.-J., Läuger, P. 1991. Charge translocation by the Na,K-Pump: II. Ion binding and release at the extracellular face. J. Membrane Biol. 121:163-176

Tanford, C., Reynolds, J.A., Johnson, E.A. 1987. Sarcoplasmatic reticulum calcium pump: A model for $\mathrm{Ca}^{2+}$ binding and $\mathrm{Ca}^{2+}$-coupled phosphorylation. Proc. Natl. Acad. Sci. USA 84:7094-7098

Vilsen, B. 1995. Structure-function relationships in the $\mathrm{Ca}^{2+}$-ATPase of sarcoplasmatic reticulum studied by use of the substrate analogue CrATP and site-directed mutagenesis. Comparison with the $\mathrm{Na}^{+} \mathrm{K}^{+}$ATPase. Acta Physiol. Scand. 154 Suppl. 624:1-146

Vilsen, B., Ramlov, D., Andersen, J.P. 1997. Functional consequences of mutations in the transmembrane core region for cation translocation and energy transduction in the $\mathrm{Na}^{+} \mathrm{K}^{+}$-ATPase and the SR $\mathrm{Ca}^{2+}$-ATPase. Annals NY Acad. Sci 834:297-309

Walz, D., Caplan, S.R. 1988. Energy coupling and thermokinetic balancing in enzyme kinetics. Microscopic reversibility and detailed balance revisited. Cell Biophys. 12:13-28

Yu, X., Carroll, S., Rigaud, J.-L., Inesi, G. 1993. $\mathrm{H}^{+}$countertransport and electrogenicity of the sarcoplasmatic reticulum $\mathrm{Ca}^{2+}$ pump in reconstituted proteoliposomes. Biophys. J. 64:1232-1242

Yu, X., Hao, L., Inesi, G. 1994. A pK change of acedic residues contributes to cation countertransport in the $\mathrm{Ca}^{2+}$-ATPase of sarcoplasmatic reticulum. J. Biol. Chem. 269:16656-16661

Yu, X., Inesi, G. 1995. Variable stoichiometric efficiency of $\mathrm{Ca}^{2+}$ and $\mathrm{Sr}^{2+}$ transport by sarcoplasmatic reticulum ATPase. J. Biol. Chem. 270:4361-4367

Zhang, P., Toyoshima, C., Yonekura, K., Green, N.M., Stokes, D.L. 1998. Structure of the calcium pump from sarcoplasmatic reticulum at 8-Å resolution. Nature 392:835-839 